\title{
PAIS OUVINTES, FILHO SURDO: CAUSAS E CONSEQUÊNCIAS NA AQUISIÇÃO DA LÍNGUA DE SINAIS COMO PRIMEIRA LÍNGUA
}

\author{
HEARING PARENTS, DEAF CHILD: CAUSES AND CONSEQUENCES OF THE \\ ACQUISITION OF SIGN LANGUAGE AS A FIRST LANGUAGE
}

\author{
PADRES OYENTES, NIÑO SORDO: CAUSAS Y CONSECUENCIAS DE LA \\ ADQUISICIÓN DE LA LENGUA DE SEÑAS COMO EL PRIMERA LENGUA
}

\author{
Denise Moura Carvalho * \\ Layane Rodrigues de Lima Santos ${ }^{* *}$
}

\begin{abstract}
Resumo
Esta pesquisa analisa o processo de aquisição de linguagem de uma criança surda filha de pais ouvintes, utilizando como referencial teórico discussões sobre teorias de aquisição da linguagem por surdos. A metodologia empregada é qualitativa pois, por meio de um estudo de caso, investiga fatores linguísticos e sociais no processo de aquisição de linguagem de uma criança surda. Foram feitas observações sobre a comunicação entre a criança surda e sua mãe ouvinte e coletado um questionário com o objetivo de saber a opinião da mãe a respeito de questões de aquisição de língua por sua filha surda. Os resultados indicam que a criança surda se comunica com a mãe mais por meio de gestos, gestos caseiros e língua oral do que por meio da Língua Brasileira de Sinais (Libras). Porém, quando há necessidade veemente de que mãe e filha se entendam, é feito o uso de gestos ou da Libras. Em consonância com os autores visitados, percebeu-se a necessidade do uso da língua de sinais como primeira língua dessa criança surda para uma efetiva e eficaz comunicação com a sua mãe. Dessa forma, este trabalho contribui para que a comunidade em geral e os pais ouvintes de crianças surdas conheçam o processo de aquisição de língua de seus filhos e busquem, a partir de estudos realizados aqui, a maneira mais saudável de estimular seus filhos a se comunicarem e se desenvolverem linguisticamente.
\end{abstract}

Palavras-chave: Libras, Surdo, aquisição de Linguagem, primeira língua.

\section{Introdução}

A Língua Brasileira de Sinais (Libras) foi reconhecida como língua há alguns anos no Brasil, por meio da Lei ${ }^{\circ}$. 10.436/02 (BRASIL, 2002), e regulamentada pelo Decreto $n^{\circ}$. 5.626/05 (BRASIL, 2005). Porém, o uso efetivo dessa língua ainda é escasso, mesmo após o

\footnotetext{
Licenciada em Letras: Libras pela Universidade Federal de Goiás - UFG. Intérprete de Libras pela Câmara Municipal de Goiânia e Professora Intérprete de Libras na Secretaria de Estado de Educação, Esporte e Lazer - SEDUCE. E-mail: dmouralsinais@gmail.com

** Mestre em Linguística pela Universidade de Brasília. Professora de Linguística e de Língua Portuguesa do Departamento de Libras e Tradução da Faculdade de Letras da Universidade Federal de Goiás e Doutoranda em Linguística pela Universidade de Brasília. E-mail: layanel@gmail.com
} 
seu reconhecimento legal. Uma possível explicação para esse fato se dá pela pouca divulgação da língua de sinais e da cultura surda. Assim, nasce um cenário muito comum na família brasileira ouvinte que tem um filho surdo: como "fazer acontecer" a comunicação dentro de casa? A partir dessa indagação, gera-se a hipótese de que a comunicação aconteça na maioria das vezes com os pais fazendo uso da voz para conversar com seus filhos e, não obtendo sucesso, utilizando a comunicação gestual.

Diante disso, a escolha do tema da pesquisa que ora se apresenta decorre de uma inquietação em torno do problema de ser garantida ou não, no contexto familiar, a comunicação em Libras, defendendo-se que esta deva ser a primeira língua (L1) da criança surda e a segunda língua (L2) dos pais ouvintes. As respostas que a família procura e os caminhos pelos quais opta diante da notícia de ter um filho surdo, além da forma como irá lidar com esta criança, tanto linguística quanto socialmente, causará significativa interferência em seu desenvolvimento linguístico. Deste modo, o presente artigo discute essas questões por meio de um estudo de caso da comunicação entre uma criança surda e sua mãe ouvinte.

\section{Aquisição da linguagem por surdos}

No Brasil, as pesquisas sobre o processo de aquisição da Libras como L1 foram iniciadas somente nos anos de 1990 (KARNOPP, 1994; QUADROS, 1995, 1997; QUADROS e CRUZ, 2011). As investigações desenvolvidas até então comprovam que as crianças surdas, filhas de pais surdos, adquirem as regras de sua gramática de modo análogo às crianças ouvintes em aquisição de línguas orais-auditivas. Os estágios em que se divide esse processo, conforme observam Quadros (1997) e Quadros \& Cruz (2011), são: período pré-linguístico, estágio de um sinal, estágio das primeiras combinações e estágio das múltiplas combinações.

O Período Pré-Linguístico está presente no momento em que a criança começa a balbuciar. De acordo com Dubois, balbucio é a sequência de sons emitida por uma criança entre um e cinco meses, não acompanhada de gritos, que apresentam uma extrema variedade sem ter ainda valor fonológico (2006, p. 84). Na criança surda, o balbucio apresenta-se de duas formas: silábico e gestual. O balbucio silábico mostra uma organização interna presente nas línguas de sinais, ao contrário do gestual, que não demonstra uma organização. O balbucio vocal é interrompido no bebê surdo, deixando abertos os caminhos para a continuação do desenvolvimento do balbucio mais presente em sua modalidade de comunicação: os gestos. Esse fator ocorre da 
mesma maneira em bebês ouvintes, porém, o balbucio que prevalece é o vocal. (QUADROS \& CRUZ, 2011).

Após o Período Pré-Linguístico, observa-se o Estágio de um Sinal que, conforme Quadros \& Cruz (2011), tem início por volta dos 12 meses de idade da criança surda, podendo se estender até os dois anos. Nota-se que a criança começa a utilizar os sinais ao expressar vontades como, por exemplo, ao pedir colo (levantando os dois braços) ou ao pedir algo (estendendo um braço e fazendo um movimento de "me dá"). Esses gestos são comuns tanto às crianças surdas quanto às crianças ouvintes.

Tendo superado o processo do Estágio de um Sinal, a criança passa a fazer suas Primeiras Combinações de Sinais. Conforme Quadros (1997), este período se manifesta a partir dos dois anos de idade na criança surda, momento em que há a combinação envolvendo dois a três sinais.

Por fim, a criança chega ao Estágio das Múltiplas Combinações. Estudos como os de Quadros (1997) identificam que esse período ocorre entre dois anos e seis meses de idade ou aos três anos. Aqui, a criança já deteve seu conhecimento de sentenças com gestos e um sinal, passou pelas primeiras combinações e já apreendeu todo esse caminho de conhecimento, período nomeado por Quadros (1997, p. 74) de “explosão do vocabulário".

Ainda conforme Quadros (1997), a compreensão da criança torna-se mais ampla, e ela demonstra isso ao falar sobre o que acontece ao seu redor, ao comentar sobre o que os outros estão fazendo e refletir sobre suas próprias atitudes, embora ainda não consiga marcar a presença de referentes no espaço (fator que leva a deduzir a falta de concordância verbal). Mais tarde, por volta dos cinco ou seis anos de idade, a criança começa a demonstrar necessidade de se expressar de maneira que o outro a entenda. É neste contexto que se nota a utilização da concordância verbal. Entre os seis e sete anos de idade a criança surda já é capaz de estabelecer uma comunicação clara, inclusive com estranhos e até mesmo influenciar o pensamento do interlocutor.

Por outro lado, compreende-se que, se a criança surda não tiver estímulos precoces, tanto sociais quanto linguísticos, no que se refere à aquisição de sua L1, o aprendizado será tardio, acarretando prejuízos especialmente em sua comunicação. 


\title{
2 Situação linguística de surdos filhos de pais ouvintes
}

Os processos de comunicação da criança surda assemelham-se à aquisição da criança ouvinte, se acontece de modo natural, com sua exposição à língua de sinais. Quando a criança surda é filha de pais surdos, a língua que aprende em seu ambiente está de acordo com as suas capacidades linguísticas, sendo-lhe a língua, portanto, acessível. Porém, como se dará esta aquisição para uma criança surda, filha de pais ouvintes sem o domínio da língua de sinais? Geralmente, em tentativas de comunicação, os pais ouvintes com filhos surdos utilizam a língua oral concomitante aos gestos. Porém, de acordo com Kail (2013), a produção linguística dessas crianças a partir dos três anos de idade é inferior a das crianças expostas à língua de sinais. A autora ressalta ainda que,

\begin{abstract}
se a exposição a uma língua falada e sinalizada pode trazer benefícios para o desenvolvimento das competências comunicativas e cognitivas da criança, em contrapartida, parece indispensável fornecer um input correspondente a uma língua integral (língua de sinais) para que as competências linguísticas possam ser elaboradas. (KAIL, 2013, p.99)
\end{abstract}

Nesta perspectiva, Quadros e Cruz (2011) salientam que o foco das pesquisas de aquisição da linguagem tem sido: filhos surdos de pais surdos. No entanto, pesquisas na área de aquisição de língua de sinais por surdos filhos de pais ouvintes têm sido também implementadas. Tal estudo mostra-se relevante devido ao processo de aquisição de língua dessas crianças ocorrer tardiamente, em decorrência de vários fatores, como aponta Kail:

\begin{abstract}
A população de crianças surdas é marcada por uma grande heterogeneidade. O grau de deficiência auditiva, a idade do dano sensorial, o estatuto auditivo dos pais (surdos ou ouvintes), os métodos de comunicação utilizados (oral exclusivo, linguagem falada completada, ou LFC, língua de sinais), bem como o tipo de escolaridade (escola especializada ou escola inclusiva) constituem os principais fatores capazes de influenciar a aquisição da língua oral (KAIL, 2013, p.96).
\end{abstract}

Assim, percebe-se o quanto é necessário o auxílio e o apoio da família na vida e no desenvolvimento da criança surda. Diante disso, Rodriguero (2013), baseada nos estudos de Schmid-Giovannini (1980), explica que:

O primeiro passo a ser dado pela família que tem uma criança surda é procurar integrá-la como membro ativo da comunidade familiar. Assim, a criança surda terá maior facilidade para integrar-se à comunidade de pessoas ouvintes. Com o apoio da 
família, o surdo encontrará menor dificuldade em conviver com pessoas ouvintes, o que lhe propiciará ser um elemento ativo desta sociedade (RODRIGUERO, 2013, p.23).

Dessa forma, sabe-se que pode haver falha na comunicação, pois "a família é compreendida como gênese na construção social das relações. É na família que a criança adquire a linguagem e a capacidade de se comunicar com os outros, sendo este núcleo primário a base das futuras interações sociais da criança” (GUARINELO et al., 2013, p. 153). Sobre a criança surda, em relação à criança ouvinte, nota-se de fato que aquela, assim como esta, aprende a linguagem, seja oral ou sinalizada, a partir do ambiente ao seu redor. Tal como a criança ouvinte cercada de falantes de Português (ou qualquer outra língua falada) e que se apoia nessa língua para desenvolver-se linguisticamente, a criança surda cercada de usuários de língua de sinais aprenderá os sinais que observar.

Assim, quando existe a necessidade da comunicação, mas não há uma língua estabelecida entre pais e criança surda, é criada uma alternativa doméstica, que não é considerada, portanto, uma língua, por se tratar de gestos inventados a partir de determinadas situações em que algo precisou ser dito ou informado. Dalcin, em seus estudos sobre gestos caseiros, cita Goldfeld, afirmando que esse pesquisador

[...] encontrou o mesmo fenômeno descrito por Behares \& Peluso, e afirma que as crianças surdas filhas de pais ouvintes criam em conjunto com a sua família alguns sinais e os utilizam para a organização de seu pensamento. Essa linguagem se dá de modo rudimentar e é desenvolvida pela criança com o objetivo de estabelecer interações sociais e uma comunicação entre ela e seus familiares e também para simbolizar e conceitualizar, buscando uma organização de pensamento (GOLDFELD, 2002, p.62 apud DALCIN, 2009, p. 26).

Os gestos caseiros, portanto, demonstram a carência de uma língua para a criança no momento em que ela mais precisa se comunicar: ao conversar com pais ou amigos, ao contar algo, tirar dúvidas ou simplesmente questionar os "porquês" sobre o que existe no mundo. Nessa perspectiva, com tantas barreiras para o desenvolvimento, principalmente linguístico, da pessoa surda, é necessário que se abra um leque de reflexões sobre o avanço das formas de ensino e aprendizado nesse contexto, já que o desenvolvimento linguístico se dá desde a primeira infância.

Grannier (2007) discorre sobre algumas propostas que tratam do aprendizado da língua de sinais pela criança surda, e também pela criança ouvinte, desde seus primeiros anos 
de vida, objetivando a comunicação de modo informal, por meio de pessoas surdas que estejam ao seu redor, propondo, por exemplo, o que chama de "creche mista", em que pelo menos dois funcionários sejam surdos, visando um aprendizado com ensino informal, no caso de bebês surdos.

\section{Metodologia}

Esta pesquisa é de cunho qualitativo, visto se tratar de um estudo de caso em que serão avaliados os dados a partir da comunicação entre indivíduos de um mesmo ambiente. Tendo em vista a possibilidade de analisar o sujeito em seu contexto específico, julgou-se conveniente para este trabalho realizar uma pesquisa de campo com vistas a investigar as relações comunicacionais entre mãe ouvinte, que aqui será chamada de Lúcia, e sua filha surda, que aqui será chamada de Bia. Ambas, mãe e filha, estão aprendendo a língua de sinais, mas se comunicam na maior parte das vezes por meio da modalidade oral da Língua Portuguesa. Salienta-se, no entanto, que as duas estão em processo de aquisição da língua de sinais - a filha aprendendo Libras como primeira língua e, a mãe, como segunda língua.

A pesquisa foi desenvolvida por meio de sete visitas ao lar dessa família, com intensa observação dos momentos de comunicação entre a criança e as demais pessoas presentes em casa. Cada observação foi anotada em um diário de campo para que, posteriormente, fossem tratadas como dados para análises. Para complementar as informações relacionadas à situação linguística da criança e obter dados anteriores ao momento da pesquisa, também foi apresentado à mãe um questionário (ver Anexo), com perguntas abertas e fechadas. Seu conteúdo foi elaborado com base em dúvidas advindas dos estudos teóricos realizados para esta pesquisa, e teve como finalidade possibilitar maior compreensão sobre: as observações registradas nas visitas à família; a visão da mãe em relação à sua filha surda e o alcance ou, ao menos, a aproximação mais fidedigna da realidade linguística vivida dia a dia entre as participantes, com situações que durante as visitas não poderiam ser vistas. A mãe aceitou responder a todas as perguntas sugeridas e, dessa forma, foram estabelecidos os critérios metodológicos para esta pesquisa. 


\section{Análise dos dados}

Durante as visitas, notou-se na criança surda a vontade e a recorrente necessidade de se comunicar. Por vários momentos, Bia buscou chamar a atenção, tentando fazer com que a mãe a olhasse e atendesse aos seus pedidos e vontades no momento em que se manifestasse.

Bia e Lúcia mantinham uma comunicação baseada principalmente nas necessidades do dia a dia, típicas do ambiente familiar, como: alimentação, vestuário, saúde, beleza etc. No entanto, essa comunicação se restringia apenas a esses assuntos, sem promover uma interação para além das necessidades de Bia, no que diz respeito à relação linguística. Lúcia sempre está aberta e disposta a ajudar a filha em tudo o que for preciso, mas, como visto na segunda parte deste artigo, que abordou a interação linguística entre pais ouvintes e filhos surdos, percebeuse que, de fato, a comunicação, na maior parte das vezes, ficava limitada às obrigações e responsabilidades dos pais.

Foi possível notar que a relação entre Bia e Lúcia envolvia o genuíno amor entre mãe e filha, inferindo-se, por conseguinte, ser o afeto um fator importantíssimo na comunicação entre ambas, especialmente no momento em que Lúcia precisava repreender Bia. Nas situações observadas, a repreensão era estabelecida oralmente (a mãe usava a voz), como também acontecia na maior parte da comunicação em geral, utilizando-se amplamente da expressão facial e de um sinal que já havia se tornado uma característica frequente na comunicação de mãe e filha nessas situações, o sinal "DESCULPA".

Em outra visita foi possível perceber a falta que faz o uso de uma língua em determinadas situações. Em um dia de sol, Bia recebeu uma colega da casa vizinha, que sempre a visitava para que brincassem juntas. Em determinado momento da brincadeira, Bia caiu do patinete e se machucou levemente. Ficou brava, estendeu os braços para baixo, pegou o patinete e o jogou de lado. Em seguida, caminhou até sua mãe, que perguntou: "Machucou? Machucou?”. A criança, muito nervosa, movimentava os braços para baixo, fazendo sons que mostravam seu nervosismo e empurrava a mãe, que lhe disse para ficar calma e entrar para beber água. Dentro de casa, chateada, ela apontava para o local machucado e reclamava, sempre oralizando de forma ininteligível.

Assim que a raiva passou, ela voltou a brincar. Novamente, outro fato ocorreu. Sem querer, a mãe que estava de costas, esbarrou na orelha da filha, fazendo (sem intenção) com que o aparelho auditivo caísse no chão. A criança olhou para a mãe com raiva, abriu bem a 
boca indicando que seu ouvido estava doendo, com a mão aberta e muito nervosa, empurrou a mãe e foi para dentro de casa.

A mãe foi atrás da menina, tentando explicar que não tinha sido culpa dela e pedindo desculpa (utilizando o sinal em Libras). Assim que voltou de dentro de casa mais calma, ela apontou para a mãe e para o seu próprio ouvido. A mãe passou a mão aberta na frente dos olhos, indicando que não tinha visto Bia passando, que não tinha sido intencional. A criança demonstrou ter entendido nesse momento que a mãe não teve culpa, que foi sem querer e então voltou a brincar. Quando a mãe utilizou o sinal de DESCULPA, notou-se o quão ele foi adequado ao momento. Aliado às expressões corporais e faciais da mãe, esse sinal ajudou a criança a entender que a culpa do ocorrido não havia sido da mãe. Que ela não queria machucá-la, amenizando assim a situação e desfazendo o mal-entendido, com a utilização desse sinal.

Durante todas as visitas, notou-se uma evolução da criança na comunicação através de gestos, em relação à utilização, tanto da Libras quanto de sinais caseiros. A mãe tinha interesse em aprender mais sobre a Língua Brasileira de Sinais e a cultura surda, demonstrando, em consonância com a literatura revisada, que quando os pais ouvintes se interessam e aprendem a Libras, para estabelecer comunicação com seus filhos surdos através de uma língua, o desenvolvimento da criança será muito maior do que se essa comunicação for feita apenas por meio de gestos ou da língua oral. Além disso, era notória a satisfação de Bia, que também estava em processo de aquisição da Libras, quando a mãe conversa com ela fazendo uso da língua de sinais. A importância da Libras no processo de aquisição da linguagem de Bia reforça, portanto, as questões teóricas aqui abordadas.

Segundo Lúcia, Bia nasceu com uma doença rara que pode ter causado a surdez. Os médicos ainda não sabem dizer com precisão, mas acreditam ser essa doença a provável causa da perda auditiva de sua filha. A perda foi gradual, segundo a mãe relata. Em seus primeiros anos de vida, a criança ainda pronunciava algumas palavras, como "mamãe" ou "papai"; depois, a mãe percebeu que o número de palavras pronunciadas foi diminuindo e, por isso, a família procurou um fonoaudiólogo. Alguns anos depois, por meio de exames, foi possível constatar que a criança havia perdido totalmente a audição. Após vivenciar vários transtornos no ambiente escolar, com falta de profissionais adequados, e se submeter às limitações comunicacionais em casa, que a mãe decidiu procurar outro tipo de ajuda: a da Libras, principal frente defendida neste trabalho. 
A mãe ressaltou alguns dos entraves de sua caminhada e reconheceu a importância da Libras para o desenvolvimento da filha, ao afirmar, respondendo à questão 6 do questionário que lhe foi apresentado: "Parece que com a fono perco tempo, porque ela [Bia] fala uma ou outra palavra, mas não adianta muito. Ela se comunica melhor com gestos do que oralmente" (ver Anexo). Ao responder a pergunta de número nove do questionário, afirmou: “A Libras é importante para o desenvolvimento dela, e é com o tempo e com estudo que ela vai se desenvolver; deveria ter aprendido desde pequena. Foi um erro ter perdido tempo" (ver Anexo).

Essas observações da mãe estão coerentes com os conceitos de nossa revisão literária, especialmente com as pesquisas de Quadros (1997) e Quadros \& Cruz (2011), bem como de outros autores citados, que pesquisaram o tema e afirmam que a melhor forma de a criança surda se desenvolver é a partir de uma comunicação que lhe seja acessível, sem forçá-la a aprender através de uma língua que não lhe permita um desenvolvimento satisfatório.

Por meio da entrevista com a mãe de Bia, foi possível perceber que a comunicação entre elas era realizada de qualquer maneira, por estarem em seu ambiente familiar, em condições favoráveis. Entre mãe e filha não havia barreiras comunicacionais capazes de impedir o estabelecimento de vínculos afetivos. Por conhecer as necessidades de sua filha, eram múltiplas as possibilidades de entendimento entre elas. Exemplo disto é o relato de Lúcia a respeito de uma situação em que, apesar de utilizarem gestos já estabelecidos durante a convivência, ainda era difícil haver entendimento. Contudo, mesmo neste cenário, mãe e filha encontraram alternativas para o diálogo. Em geral, Bia se esforçava para tornar claro o que desejava comunicar, fazendo-o de qualquer maneira, como Lúcia explica, ao responder a oitava pergunta: “Quase tudo que ela diz dá pra eu entender, mas, quando eu não entendo, ela fica brava! Por exemplo: uma vez ela me pediu água. Peguei a água e levei pra ela no quarto. Quando cheguei lá, ela não bebia, e ainda ficava brava. Eu não entendia o porquê. Foi então que ela desenhou o copo em específico que queria tomar a água. Então, de uma forma ou de outra, a gente se entende", disse a mãe (ver Anexo).

Lúcia contou que estava estudando Libras e, ao final do questionário, sugeriu a outros pais ouvintes de crianças surdas que procurassem ajuda com os profissionais adequados, que conhecessem a realidade das crianças surdas e que fizessem um curso de língua de sinais.

Percebeu-se o notável interesse da mãe em procurar a ajuda necessária para encontrar a melhor forma de desenvolvimento linguístico e para sua filha e, consequentemente, sua 
melhor integração social, juntamente com o reconhecimento da importância da Libras para a vida de Bia. Os estágios de aquisição de linguagem, apresentados na primeira parte deste trabalho, são determinados por fatores como a interação entre as pessoas que estão em volta da criança, a interação com a própria criança e também por fatores internos, que advêm dos processos da mente humana, como a faculdade da linguagem, como postulou o linguista norte-americano Noam Chomsky (1957), pois todo ser humano é dotado de capacidade linguística e, portanto, deve ser estimulado para se desenvolver satisfatoriamente.

Foi assim que se mostrou Lúcia: aberta para o aprendizado de uma nova língua, mas não de uma língua qualquer: a língua que permite comunicação entre ela e sua filha. Dessa forma, Lúcia se mostra convicta das respostas que deu às perguntas do questionário, one afirma que a Libras seria uma ótima forma de desenvolvimento para Bia e também durante todas as visitas feitas para coleta de dados, em que foi perceptível a necessidade do uso da Libras e de gestos para que a comunicação ocorra sem falhas e seja eficiente. Inicialmente a comunicação entre mãe e filha acontecia através de sons, com a utilização da língua oral, mas logo se tornou evidente que a compreensão só era satisfatória se fossem usados acenos, gestos ou sinais para complementar o entendimento.

\section{Considerações finais}

Ao se investigar as percepções da família ouvinte em relação à criança surda, procurou-se observar se havia, da parte dos pais, a consciência de que, ao impedir a aquisição da Libras ou restringir seu espaço dentro de casa, pela falta de conhecimento da língua ou pelo esforço de negação da surdez da criança, poderiam estar prejudicando seu aprendizado.

É parte fundamental do desenvolvimento da identidade do surdo a escolha de sua modalidade de comunicação. Ao ignorar sua habilidade visuoespacial, que tem a Libras como caminho de desenvolvimento, e tomar como modalidade de comunicação a língua oral, a criança surda acaba sofrendo por essa má escolha. Nesses casos, a família costuma ser a maior responsável pelas consequências que afetam a criança ao longo de sua vida. No que diz respeito aos âmbitos comunicacional e social, isso pode impactar seu presente e seu futuro. Quando o surdo encontra, em sua infância, falta de apoio para desenvolver-se, os ecos deste início de aprendizado prejudicado serão identificados por toda a sua vida, sendo mais difícil, para o surdo, encontrar o seu próprio caminho. 
Tendo em vista que o ser humano aprende e se desenvolve a partir das interações humanas, conversas, diálogos, e que esta interação ocorre principalmente onde cada um vive e conhece pessoas, é possível perceber que, desde pequenas, as crianças veem adultos conversando, contando histórias, estabelecendo regras de brincadeiras, ou ainda, aprendem brincando com outras crianças, com as histórias dos mais velhos, efetivando assim seus primeiros contatos com sua língua, ou seja, a língua à qual está exposta nestas situações. No entanto, se o canal de comunicação da criança surda não for o mesmo de seus familiares, a língua à qual ela está exposta não será correspondente a sua língua. Isso só seria possível se seus familiares aprendessem sua língua natural.

Observou-se que não apenas a criança surda deve fazer o uso da Libras em seu lar, mas também sua família, pois ela precisa interagir com as pessoas com quem convive. Precisa falar, sinalizar, utilizar gestos caseiros e, por conseguinte, obter uma resposta a essas interações. Esse é um estímulo essencial, que pode ser provocado principalmente pelos pais da criança, visto que sua família é o referencial necessário para que ela se sinta bem e capaz de se comunicar, desenvolvendo-se nos âmbitos sociais, linguísticos e educacionais.

Essa pesquisa procurou mostrar a diferença que o estímulo da língua de sinais traz à vida de uma criança surda, apresentando-lhe um mundo que antes parecia distante: o mundo ouvinte. Com a língua de sinais, as informações chegam até ela, sem a necessidade de se esforçar para dizer, com muita dificuldade, palavras que lhe são estranhas, vozes imperceptíveis, mas que tomam forma quando se transformam em sinais, compondo-se na sua língua, na língua que a liga à sua família. Também se buscou demonstrar, por vias teóricas e de campo, as modalidades mais indicadas de comunicação para uma criança surda, para que sua comunicação seja eficaz.

Neste estudo de caso, constatou-se que, por causa do acesso tardio à Libras, a criança surda observada apresentava alguma dificuldade para se comunicar, devido a algumas restrições linguísticas da mãe, sua comunicação estava limitada aos gestos combinados, ou não, com a mãe e a alguns sons. Retoma-se, dessa forma, a importância de uma proposta feita por Grannier, citada na segunda parte deste artigo, que propõe a criação de creches mistas, nas quais todos do grupo docente saibam Libras e que também haja pessoas surdas entre eles. Essa é uma boa maneira de trazer para a criança surda um mundo que ainda lhe é novo e, se essa ideia fosse empreendida em várias cidades, possibilitaria às crianças, e aos seus pais, a oportunidade de evoluir na aquisição da linguagem. 
Ter a Libras como primeira língua, como no estudo de caso ora apresentado, permite a estas crianças o acesso a outras línguas existentes no Brasil e no mundo, a diferentes culturas, sociedades, ficções e, o principal, favorece o desenvolvimento de sua própria vida, contando com suas próprias escolhas, cenário que o uso da língua oral não poderia lhe proporcionar.

\begin{abstract}
This research analyzes the process of language acquisition of a deaf child, the daughter of hearing parents. The theoretical reference starts from the discussions about theories of language acquisition by deaf people. The methodology is qualitative, through a case study that investigates linguistic and social factors on the language acquisition process of a deaf child. We observed the communication between the deaf child and her mother were, and a questionnaire was applied, aimed at collecting the opinion of the mother about some questions about the language acquisition of her deaf daughter. The results indicate that the deaf child uses more gestures, homemade gestures and oral language to communicate with her mother than the Brazilian Sign Language (Libras). However, when there is the vehement need of understanding between the mother and daughter, they use gestures or Libras. According to the visited authors, we noticed the need for Sign Language as this child's first language, for an effective and efficient communication with her mom. Thus, this work contributes to the community in general and the hearing parents of deaf children get to know their child's process of language acquisition, and seek, starting on this study, the most healthy way to stimulate their child to communicate and start their linguistic development.
\end{abstract}

Keywords: Libras, Deaf People, language acquisition, first language.

\title{
Resumen
}

Esta investigación analiza el proceso de adquisición del lenguaje de una niña sorda, hija de padres oyentes, tomando como base teórica debates sobre las teorías de adquisición del lenguaje de sordos. Se usa la metodología cualitativa, pues a través de un estudio de caso se investigan los factores lingüísticos y sociales en el proceso de adquisición del lenguaje de una niña sorda. Se observó la comunicación entre la niña sorda y su madre oyente y se recogió un cuestionario con la finalidad de conocer la opinión de la madre acerca de los problemas de adquisición del lenguaje por su hija sorda. Los resultados indican que la niña sorda se comunica con su madre más a través de gestos, gestos caseros y lenguaje oral y por intermedio de la Lengua Brasileña de Señales (LIBRAS). Pero cuando es necesaria la comprensión entre madre e hija usan gestos o libras. En acuerdo con los autores consultados, percibimos que la necesidad del uso de la lengua de señas, como primera lengua de esa niña sorda, para una comunicación efectiva y eficiente con su madre. Por lo tanto, este trabajo contribuye para que la comunidad en general y los padres oyentes de niños sordos conozcan el proceso de adquisición del lenguaje de sus hijos y busquen, a partir de los estudios aquí realizados, la forma más saludable de animar a sus hijos a comunicarse y desarrollarse lingüísticamente.

Palabras clave: Libras, Sordo, adquisición del lenguaje, primera lengua. 


\section{Referências}

BRASIL. Decreto $n^{\circ}$ 5.626, de 22 de dezembro de 2005. Regulamenta a Lei $\mathrm{n}^{0} 10.436$, de 24 de abril de 2002, que dispõe sobre a Língua Brasileira de Sinais - Libras, e o art. 18 da Lei no 10.098, de 19 de dezembro de 2000. Diário Oficial [da] União, Brasília, DF, 23 dez. 2005. Disponível em:

<http://www.planalto.gov.br/ccivil_03/_ato20042006/2005/decreto/d5626.htm>. Acesso em: 15 jul. 2015.

BRASIL. Lei $\mathrm{n}^{0}$ 10.436, de 24 de abril de 2002. Dispõe sobre a Língua Brasileira de Sinais Libras e dá outras providências. Diário Oficial [da] União, Brasília, DF, 25 abr.2002.

Disponível em: <http://www.planalto.gov.br/ccivil_03/leis/2002/L10436.htm>. Acesso em: 10 mai. 2015.

CHOMSKY, Noam. Syntactic Structures. The Hague: Mouton, 1957.

DALCIN, Gladis. Psicologia da Educação dos Surdos. Apostila usada na Universidade Federal de Santa Catarina. Licenciatura Letras: Libras. 2009. Unidade II.

DUBOIS, Jean et al. Dicionário de Linguística. [direção e coordenação geral da tradução Izidoro Blikstein]. São Paulo: Cultrix, 2006.

GRANNIER, Daniele Marcelle. A jornada linguística do surdo da creche à universidade. In: KLEIMAN, Ângela \& CAVALCANTI, Marilda (orgs.). Linguística Aplicada: suas faces e interfaces. Campinas, SP: Mercado de Letras, 2007. p. 199 - 216.

GUARINELO, Ana Cristina et al. Reflexões sobre as interações linguísticas entre familiares ouvintes - filhos surdos. In: Tuiuti: Ciência e Cultura, n. 46, Curitiba, 2013.

KAIL, Michèle. Aquisição de linguagem. Tradução Marcos Marcionilo. 1. ed. São Paulo: Parábola, 2013.

KARNOPP, Lodenir Becker. Aquisição do parâmetro configuração de mão dos sinais da língua brasileira de sinais: estudo sobre quatro crianças surdas filhas de pais surdos. Dissertação de Mestrado, Instituto de Letras e Artes. PUCRS. Porto Alegre, 1994.

QUADROS, Ronice Müller. As categorias vazias pronominais: uma análise alternativa com base na LIBRAS e reflexos no processo de aquisição. Dissertação de Mestrado. PUCRS. Porto Alegre, 1995.

QUADROS, Ronice Müller. Educação de Surdos: a aquisição da linguagem. Porto Alegre: Artmed, 1997.

QUADROS, Ronice Müller; CRUZ, Carina Rabello. Língua de sinais: instrumentos de avaliação. Porto Alegre: Artmed, 2011. 
RODRIGUERO, Celma Regina Borghi. A Família e o filho surdo: uma investigação acerca do desenvolvimento psicológico da criança segundo a abordagem histórico-cultural. 1. ed. Curitiba, PR: CRV, 2013.

\section{Anexo}

\section{Questionário:}

1. Durante sua vida, em suas experiências, já havia lidado ou convivido com alguma pessoa surda ou teve interesse em aprender Língua Brasileira de Sinais (Libras)?

2. Quando você descobriu que seu filho (a) era surdo? Qual foi a sua reação? E, em relação à comunicação com seu filho (a), pensou de imediato como seria ou nem chegou a pensar no assunto?

3. Como acontece a comunicação com seu (sua) filho (a)?

4. Você conhece Libras ou alguma outra forma de comunicação que utilize a linguagem visuoespacial?

5. Hoje, seu filho (a) faz algum curso de Língua de Sinais ou tem atendimento com o fonoaudiólogo?

6. De que maneira você acha que seu filho (a) está se desenvolvendo melhor? Fale sobre o desenvolvimento dele (a) em Libras e sobre seu desenvolvimento com o fonoaudiólogo, caso a resposta para esta questão seja sim.

7. Você acha necessário que seu filho (a) frequente o fonoaudiólogo e faça terapias que o estimulem a utilizar a fala oral? Explique.

8. Quando seu filho (a) lhe pede algo, conversa, ou tenta lhe explicar alguma situação, por exemplo, contar uma história, você consegue entender claramente e manter o diálogo? Se sim, como ocorre essa comunicação?

9. Em sua opinião, você acha que seu filho conseguirá se desenvolver fazendo o uso da Língua de Sinais como sua primeira língua? Se sua opinião for não, explique o porquê, e se for sim, comente sobre como você acredita que a Libras ajudará no desenvolvimento da criança.

10. Você faz ou já fez curso de Libras? Sim ( ) Não ( )

Se a resposta for sim, responda: De que maneira você se comunica com a criança fazendo uso dos sinais que aprende no curso?

11. Quando utiliza os sinais de forma clara com a criança, percebe que ela copia os sinais mesmo sem entender o real significado, ou ela ignora e continua se comunicando de outra forma?

12. Quais orientações você daria a famílias ouvintes com filhos surdos no que se refere à comunicação?

13. Outros comentários: 